\title{
P-4
}

\section{Domestication of Osbeckia octandra}

\author{
Meneripitiya M.S.K. ${ }^{*}$ and Jayatilleke M.P. \\ Department of Botany, Faculty of Science, University of Kelaniya, Kelaniya, Sri Lanka \\ *86.sarani@gmail.com
}

\begin{abstract}
Osbeckia octandra (Melastomataceae) is a rare endemic perennial plant with a high medicinal value which can also be used as an ornamental species as it bear beautiful violet colour flowers. Though the availability of these plants have restricted to certain areas of the country and has a limited distribution it should be propagated using successful mass propagation techniques.

Osbeckia octandra found at the Pilikuththuwa forest reserve located in Gampaha district, Sri Lanka was use in this study. Stem cuttings of $O$. octandra with 4 to 5 nodes were tested using different potting mixtures (sand alone, compost: sand (1:1) and compost: coir dust (1:1) to determine the best growth medium for vegetative propagation. Length of roots, number of roots and the dry weights of roots were measured after four months of the growth.

Based on one way ANOVA analysis it was observed that there was a significant difference $(\mathrm{P}<0.05)$ between the three media compositions used on rooting of stem cuttings. Tukey's pairwise comparison proved, mean root lengths, mean number of roots and mean root dry weights of stem cuttings planted on compost: coir dust medium at the fourth month differ significantly from sand medium and the compost: sand medium. Compost: coir dust (1:1) medium produced the highest number of roots, highest length and highest dry weights of roots of stem cuttings. From the results obtained it could be suggested that out of all three media used compost: coir dust (1:1) was the most suitable medium for rooting of O. octandra stem cuttings.
\end{abstract}

Keywords: Osbeckia octandra, Vegetative propagation, Potting mixtures 